\title{
Consumers' Shares of Preferences for Turfgrass Attributes Using a Discrete Choice Experiment and the Best-Worst Method
}

\author{
Monika Ghimire ${ }^{1,4}$, Tracy A. Boyer ${ }^{2}$, and Chanjin Chung ${ }^{3}$ \\ Department of Agricultural Economics, Oklahoma State University, \\ Stillwater, OK 74078 \\ Justin Q. Moss ${ }^{2}$ \\ Department of Horticulture and Landscape Architecture, Oklahoma State \\ University, Stillwater, OK 74078
}

Additional index words. turfgrass attributes, preference share, discrete choice experiment, best-worst method

\begin{abstract}
This study compares preference shares of stress-tolerant, low-maintenance, and low-cost turfgrass attributes in five states (Florida, Georgia, North Carolina, Oklahoma, and Texas) in the southeastern and midsouthern United States using the discrete choice experiment (DCE) and the best-worst method (BWM). An online survey was conducted and a mixed logit model (MLM) was used to determine the homeowners' relative preferences for turfgrass attributes. The results of a survey of 1179 household consumers indicate that the most preferred attribute using either of the methods was low maintenance cost in all the states. Although the relative importance (preference share) by the DCE and the BWM for each attribute is statistically different, both methods yield a similar preference ordering for low-maintenance, drought-tolerant, and saline-tolerant turf, but a different ordering for shade-tolerant and low purchase-price turf. This study provides a framework for turfgrass researchers and producers to invest and expand outreach on desirable turfgrass attributes for homeowners.
\end{abstract}

The turfgrass industry is expanding rapidly as one of the fastest growing segments of agriculture sales in the United States due to its aesthetic benefits for residential and commercial properties (Haydu et al., 2006; Morris, 2003). The total value of turfgrass production in the five states in this study (Florida, Georgia, North Carolina, Oklahoma, and Texas) comprised $\$ 404,821,402$ in sales in 2012 (USDA-NASS, 2015). Apart from providing an aesthetically pleasing surface for outdoor activities, turfgrass is also used for

\footnotetext{
Received for publication 30 Mar. 2016. Accepted for publication 25 May 2016.

This project was supported by the National Institute of Food and Agriculture, Specialty Crops Research Initiative, U.S. Department of Agriculture (USDA) under award number 2010-51181-21064 and USDA Hatch Project OKL02852.

This project comprises a coordinated agricultural project team, which includes turfgrass breeders, extension specialists, plant physiologists, soil scientists, and agricultural economists from five major universities across the southern United States. We are thankful to all the team members who participated in the research. We are thankful to Dr. Jayson Lusk (Oklahoma State University) for his review and suggestions.

${ }^{1}$ Postdoctoral Fellow.

${ }^{2}$ Associate Professor.

${ }^{3}$ Professor

${ }^{4}$ Corresponding author. E-mail: monika.ghimire@ okstate.edu.
}

soil stabilization, water conservation, air and water filtration, and heat dissipation in urban areas. However, lawns occasionally create environmental externalities due to overuse of inputs like chemical fertilizer, pesticides and herbicides, high water use, and solid waste (Bormann et al., 2001).

A study by Milesi et al. (2005) found that three times more lawn is grown than any other irrigated crop in the United States, or $\approx 163,812 \mathrm{~km}^{2}$, making turfgrass the largest irrigated crop in the United States. According to the U.S. Geological Survey, of the 26 billion gallons of water consumed daily in the United States, $\approx 7.8$ billion gallons $(30 \%)$ are devoted to outdoor uses, mainly landscaping (Solley et al., 1998; Vickers, 2001). About $40 \%$ to $75 \%$ of household water use is used for turfgrass irrigation in arid and semiarid regions (Ferguson, 1987; Mayer et al., 1999; Morris, 2003).

In the context of weather variability, climate change, drought, and reduced water supplies, lawn maintenance has become a challenge. During drought and water shortages, municipalities often prohibit the use of potable freshwater on the turfgrass landscape, considering it a low priority (Kjelgren et al., 2000). Many cities have imposed mandatory irrigation restrictions, water audits, water bans, and increased prices for potable water to minimize water scarcity during droughts and to meet long-term water demand (Kenny et al., 2009). Thus, the shortage of freshwater or municipally treated water has compelled homeowners to use effluent or low quality water such as rainwater or reclaimed water for lawn irrigation purposes. Proper turfgrass management is also affected by several problems such as salinity, shade, winter stress, and high maintenance cost. The use of low quality water in hot and dry climates (drought conditions) may cause higher concentrations of salt in soil profile which not only adversely impacts turfgrass growth but also increases the maintenance cost. In addition, use of salt for road thawing in winter or intrusion of seawater in the coastal cities also increases the salinity problem in turfgrass (Murdoch, 1987). Furthermore, many home lawns have been adversely impacted by shade (Harivandi and Gibeault, 1996). Loss of turfgrass during winter due to freezing temperatures, termed as winterkill, is also another major problem of lawns (Frank, 2013). It is, therefore, necessary to develop more water-efficient and sustainable turfgrass cultivars that have wider geographical adaptability and are tolerant to several environmental stresses (drought, salinity, shade, and winterkill) to cope with environmental stresses and to better maintain turfgrass. This drives the demand for more innovative turf types that can tolerate stress and are economical to maintain (Yue et al., 2012). However, turfgrass breeders and producers desire more quantitative data on marketability of turfgrass traits to guide research in times of uncertain budgets (D. Martin, personal communication).

Determining consumers' preferences for product characteristics has gained increasing attention in decision-making and public policy. Prioritizing the importance for marketed agricultural goods is necessary to understand and manage the outcomes of research in publicly funded research in variety development. Developing and releasing a product depends on the desirability of the product to consumers compared with other products with similar characteristics, in this case, turfgrass, developed over years and decades of research. This current study of how consumers' prioritize several turf cultivars emphasizing shade, drought, winterkill, and saline tolerance in warm-season turfgrasses will help researchers focus on developing and marketing of highly desirable cultivars. Targeting research will maximize the benefit of publicly and privately funded turfgrass research and marketing efforts. Thus, the specific objective of this study is to identify the shares of preferences for stress-tolerant, low-maintenance, and low-cost turfgrass attributes from homeowners' perspectives in five states (Florida, Georgia, North Carolina, Oklahoma, and Texas) in the southeastern and midsouthern United States.

Public preferences for different products or the attributes of a product are usually elicited by direct or indirect valuation methods. Some of the most popular and relevant methods to elicit and rank consumers' preferences in 
hypothetical scenarios are the DCEs and the ranking methods such as BWM (Bleichrodt, 2002). The DCE is a stated preference method which allows us to not only analyze consumers' preferences, but also to determine the shares of preferences of the attributes used in the experiment. The shares of preferences indicate the relative importance of the attributes used in the study ranging from 0 to 100 in percentage form. Shares of preferences for all the attributes total $100 \%$. The shares of preferences of attributes can be determined by measuring the utility (part-worth) of attributes in various combinations of choices made (Louviere et al., 2000; Louviere and Woodworth, 1983). The $\mathrm{BWM}$ is a direct preference elicitation method that measures the subjective dimension, such as "degree of importance" or "degree of interest" (Auger et al., 2007). The BWM is a relatively simple method that yields coefficients for each attribute that can be used to determine the shares of preferences as the forecasted probability of the attributes.

Both the DCE (Cheraghi et al., 2008; Lancsar and Louviere, 2008; Ryan and Gerard, 2003) and the BWM (Flynn et al., 2007; Goodman et al., 2005; Lusk and Briggeman, 2009) have been widely used to determine the shares of preferences of attributes separately. Although some comparative DCE-BWM studies have been performed on the health technology sector (Potoglou et al., 2011; Whitty et al., 2014), there are few studies that focus on their relative performance in the agricultural sector goods like turfgrass, an essential component of many residential homes and always in demand. This study reports an empirical comparison of the DCE and the BWM using data collected from a survey conducted to elicit homeowners' values for different turfgrass attributes and compares the two methods directly using shares of preference for the turfgrass attributes in five states (North Carolina, Florida, Georgia, Oklahoma, and Texas) in the southeastern and midsouthern United States.

\section{Materials and Methods}

\section{Homeowners survey}

To determine the shares of preferences that homeowners place on the turfgrass attributes, we used standard design formats in the BWM and the DCE (Finn and Louviere, 1992; McFadden and Train, 2000). In both the DCE and the BWM, respondents were presented with a number of different profiles of turfgrass attribute combinations. Attributes for the profiles were initially derived from a literature review on preferences of turfgrass attributes for lawns (Yue et al., 2012) and with consultation with a panel of breeders, physiologists, and other experts working in the turfgrass industry. Yue et al. (2012) used a choice experiment with real turf products to assess consumers' willingness to pay (WTP) for low input and aesthetic attributes of turfgrass. They reported that consumers' preferences and WTP are high for aesthetically pleasing and low maintenance attributes of turfgrass. Yue et al. (2012) were able to conduct a small group panel study with actual appearance. This study and the panel of experts chose to use a similar maintenance attribute and a different set of study-specific attributes including saline, winter, and shade tolerance to meet the funding objectives. The six turfgrass attributes [lost lawn area to winterkill, shade tolerance, watering your lawn (gallons/month), sod tolerance to salinity, maintenance and reoccurring costs (mowing, spraying, grooming, fertilizing, and weeding), and the total average purchase price for lawn of 5000 square feet and their corresponding levels] for the DCE were chosen after consultation with the expert panel and in collaboration with the Oklahoma State Turf Team (Table 1). The BWM attribute levels were simplified to represent the same attributes as in the DCE, by necessity of the difference in methods, the BWM attributes do not have corresponding levels of the DCE (Table 2).

A web-based online survey was conducted with homeowners from Florida, Georgia, North Carolina, Oklahoma, and Texas in Nov. 2013. Each survey included six BWM questions with each question containing three different options for different warm-season turfgrass attributes. The six DCE questions, each containing three different options, were followed by general and demographic questions. Respondents were asked to put themselves in the hypothetical position that they were buying turf for their lawns. A total of 1179 completed internet surveys programmed in Qualtrics using a convenience sample from Survey Sampling International were received.

\section{Survey design}

Discrete choice experiment. The experimental design for the DCE is similar to Louviere et al. (2000). Six measurable attributes associated with turfgrass adoption ranging from 2 to 4 levels were identified. A description of the attributes and levels and the number of levels are provided in Table 1. These attributes and levels create $4^{1} \times 3^{3} \times 2^{2}=432$ possible combinations of attributes. However, a fractional factorial design that consists of 18 choice sets of turfgrass attribute profiles with a D-efficiency of $96.4 \%$ was used. Three surveys were created with each containing six different sets of the DCE choice set. Each DCE choice set had three different options (A, B, and C). Options A and $B$ contained the combination of turfgrass attributes and its different levels (turfgrass attribute profiles), and option $\mathrm{C}$ represented the status quo or a no change option. For each choice set, respondents were asked to choose one of the three options. An example of the DCE choice set is provided in Fig. 1.

Best-worst method. Similar to the DCE, an experimental design method was used to create the set of the BWM choice sets. The balanced incomplete block design (BIBD) method was used with the six attributes of turfgrass (Table 2). The BIBD design focuses on the balanced design where the attributes appear an equal number of times and in equal proportion to all other attributes. The almost optimal BIBD was constructed using PROC FACTEX in SAS Software (SAS Institute Inc., Cary, NC) which is made up of six choice sets, with each containing three attributes. For the BWM task, participants were asked to choose their most and least important turfgrass attributes out of three attributes for their lawns. Each respondent's choice was coded as a 1 for each best-worst pair combination, and zero was coded for each possible pair not chosen. An example of the BWM choice set is provided in Fig. 2.

Econometric model. The MLM is used to determine the utility of each attribute of the turfgrass for both the DCE and the BWM. The MLM has different parameters for each respondent (Hensher and Greene, 2003; McFadden and Train, 2000), whereas the conditional logit model assumes that each respondent has the same parameters.

Discrete choice experiment. In the random utility theory, an individual $i$ 's utility from choosing alternative $j$ and choice set $s$ is

$$
U_{i j}=X_{i j s} \beta_{i j s}+\varepsilon_{i j s}
$$

where $X_{i j s}$ is the vector of the turfgrass attributes that describes and represents the characteristics of alternative $j, \beta_{i j s}$ is the parameter vector of the turfgrass attributes, and $\epsilon_{i j s}$ is the independent and identically distributed error term that follows a type I extreme value distribution. Allowing model

Table 1. Turfgrass attributes and levels for the discrete choice experiment.

\begin{tabular}{llll}
\hline No. & \multicolumn{1}{c}{ Attributes } & \multicolumn{1}{c}{ Attribute levels } \\
\hline 1 & Lost lawn area to winterkill (50\% probability) & $0 \%, 20 \%, 40 \%$ \\
2 & Shade tolerance & Yes, no & No. of levels \\
3 & Watering your lawn (gallons/month) & Low (20,000 gallons), medium (40,000 gallons), \\
& high (60,000 gallons) & 2 \\
4 & Sod tolerance to salinity & Yes, no & 2 \\
5 & Maintenance and reoccurring cost (mowing, & $20 \%$ less than now, 20\% more than now, no change \\
& $\quad$ spraying, grooming, fertilizing, and weeding) & 2 \\
6 & Total average purchase price for a lawn of 5,000 square feet $\left(\$ / \mathrm{ft}^{2}\right)$ & $\$ 0.20, \$ 0.40, \$ 0.60, \$ 0.80$ & 3 \\
\hline
\end{tabular}


parameters to vary randomly over individuals, the MLM is characterized by accommodating heterogeneity as a continuous function of parameters. The MLM incorporates unobservable heterogeneity by modeling a distribution of $\beta_{i}$ as:

$$
\beta_{i k}=\beta_{k}+\sigma_{k} \eta_{i k}
$$

The (relative) utility associated with each individual $i$ for attribute $k$ is represented in the DCE by a utility expression of the general form in Eq. (2), where $\eta_{i k}$ is an error term with distribution $f\left(\eta_{i k}\right)$. Hence, $\beta_{i k}$ is a random variable with distribution $f\left(\beta_{i k}\right)$, mean $\beta_{k}$, and standard deviation $\sigma_{k}$. The distribution function can take any form such as normal, lognormal, etc., which is chosen by the researcher. In this study, we use the normal distribution for all attributes. The multidimensional integral does not have a closed form so that the probability can only be achieved with simulation, and parameters are determined by maximizing the simulated log likelihood function. The distribution simulation is based on 200 pseudorandom Halton draws.

In the DCE experiment, we can characterize the share of preference or relative importance for each attribute. This task can be done by considering how much difference each attribute could make in the total utility of a product (Orme, 2010). The difference is the range in the attribute's utility (part worth) values. The percentages from relative ranges are calculated, obtaining a set of attribute importance values that total $100 \%$. The share of preference for each attribute is calculated as follows:

Table 2. Turfgrass attributes for the best-worst method.

\begin{tabular}{ll}
\hline No. & \multicolumn{1}{c}{ Attributes } \\
\hline 1 & Sod that is tolerant to drought \\
2 & Sod that is tolerant to winterkill \\
3 & Sod that is tolerant to shade \\
4 & Sod that requires low average maintenance and reoccurring cost (like cost for mowing, spraying, \\
& $\quad$ grooming, and weeding) \\
5 & Sod that is tolerant to salinity (salty soil or water) \\
6 & Sod with low average purchase price $\left(\$ / \mathrm{ft}^{2}\right)$ \\
\hline
\end{tabular}

$$
\mathrm{SP}_{k}=\frac{\widehat{R N}_{k}}{\sum_{k=1}^{6} \widehat{R N}_{k}}
$$

where $\mathrm{SP}_{k}$ is the share of preference of the $k^{\text {th }}$ attribute, and $R N$ is the range of the utility coefficients for the attribute. Relative preference represents the magnitude of preference of an attribute which contributes to a consumer's valuation and purchasing decision. After the MLM is estimated, the estimated parameters are used as a prior and the person's actual choices from the DCE method are used as a posterior. The shares of preferences are estimated at the mean of Eq. (3) evaluated in 1000 random draws. The random draws following a normal distribution are generated using the estimated means and standard deviations of the MLM as in Eq. (2). This Bayesian calculation allows for a conditional distribution on a person's actual choice as discussed by Train (2003).

Best-worst method. Choosing the item that maximizes the difference in utility is a main assumption of the BWM. A choice set with $T$ items, results in $T(T-1)$ tools or possible combinations of a set of best and worst items in a choice set. If $\lambda_{t}$ is the location of the value $t$ on the underlying scale

Options A and B represent two different sets of sod/turfgrass characteristics. Which option

\begin{tabular}{|c|c|c|c|}
\hline Attributes & Option A & Option B & Option C \\
\hline $\begin{array}{l}\text { Lost lawn area to winter kill ( } 50 \% \\
\text { probability) }\end{array}$ & $40 \%$ & $20 \%$ & \multirow{6}{*}{$\begin{array}{l}\text { If A or B were the } \\
\text { only available } \\
\text { options, } \\
\text { I would not } \\
\text { purchase new sod } \\
\text { for my lawn }\end{array}$} \\
\hline Sod tolerant to shade & Yes & No & \\
\hline $\begin{array}{l}\text { Watering your lawn } \\
\text { (gallons/month) }\end{array}$ & Low $(20,000$ gallons $)$ & High (60,000 gallons) & \\
\hline $\begin{array}{l}\text { Sod tolerant to salinity (salty water } \\
\text { or soil) }\end{array}$ & No & Yes & \\
\hline $\begin{array}{l}\text { Maintenance and reoccurring cost } \\
\text { (like mowing, spraying, grooming, } \\
\text { fertilizing, and weeding, excluding } \\
\text { purchase price) }\end{array}$ & No change & $20 \%$ more than now & \\
\hline $\begin{array}{l}\text { Total average purchase price of } \\
\text { sod for } 5,000 \text { square foot lawn } \\
\left(\$ / \mathrm{ft}^{2}\right)\end{array}$ & $\$ 0.20$ & $\$ 0.40$ & \\
\hline
\end{tabular}

(A, B or C) would you be most likely to purchase?

Fig. 1. An example of the discrete choice experiment choice set.

If you were to buy sod/turfgrass for your lawn, please check your most preferred and least preferred

sod/turfgrass characteristic out of the following choices:

(Check only one that is most preferred and one that is least preferred.)

\begin{tabular}{|c|c|c|}
\hline Most Preferred & Least Preferred \\
\hline$\square$ & $\begin{array}{c}\text { Sod that is tolerant to salinity } \\
\text { (salty water or soil) }\end{array}$ \\
\hline$\square$ & Sod that is tolerant to winter kill & $\square$ \\
\hline$\square$ & Sod that is tolerant to shade & $\square$ \\
\hline
\end{tabular}

Fig. 2. An example of the best-worst method choice set. 
of importance, then the true level of importance is $\mathrm{I}_{i t}=\lambda_{t}+\varepsilon_{i t}$, where $\epsilon_{i t}$ is an error term with an extreme value distribution (Finn and Louviere, 1992; Lusk and Briggeman, 2009). The probability that the consumer chooses to maximize the distance between items $t$ and $k$, i.e., as the best and worst out of $T$ items is the probability (i.e., difference in $\mathrm{I}_{i t}$ and $\left.\mathrm{I}_{i k}\right)$, is greater than all other $T(T-1)-1$ possible differences in that choice set which takes a conditional logit form as follows:

$\operatorname{Prob}(t$ is most preferred and $k$ is least preferred)

$$
=\frac{e^{\lambda_{t}-\lambda_{k}}}{\sum_{l=1}^{t} \sum_{m=1}^{t} e^{\lambda_{l}-\lambda_{m}}}-T
$$

where $m$ are the pair of attributes seen, but not chosen as the maximizing pair. The $\lambda_{t}$ is estimated by maximum-likelihood estimation based on the probability statement in Eq. (4). That is, the dependent variable takes the value of 1 for the pair of attributes chosen by the consumer as best and worst, and a 0 for the remaining $T(T-1)-1$ pairs of items in the choice set that were not chosen as best and worst. The estimated $\lambda_{t}$ represents the importance of attribute $T$ relative to some attributes that are normalized to zero to prevent the "dummy variable trap." In the mixed logit form, the relative importance of each individual can be identified as:

$$
\hat{\lambda}_{i t}=\bar{\lambda}_{i t}+\sigma_{t} \eta_{i t}
$$

where $\bar{\lambda}$ and $\sigma$ are the mean and standard deviation of $\lambda_{t}$ in the population, and $\eta_{i t}$ is the normally distributed random term with mean zero and unit standard deviation. Similar to the DCE, the BWM distribution simulation is also based on 200 pseudorandom Halton draws.

The share of preference for each attribute of turfgrass in the BWM can be calculated as the forecasted probability that each attribute is picked as the most important using the following equation:

$$
\text { Share of preference for attribute } t=\frac{e^{\hat{\lambda}_{t}}}{\sum_{l=1}^{t} e^{\hat{\lambda}_{t}}}
$$

Similar to the DCE, after the MLM is estimated, the estimated parameters are used as a prior and the person's actual choices from the DCE method are used as a posterior. The share of preferences are estimated on the mean of Eq. (6) evaluated in 1000 random draws. The random draws following a normal distribution are generated using the estimated means and standard deviations of the MLM as in Eq. (5).

Comparing the share of preference in the $D C E$ and the $B W M$. The shares of preference for each attribute obtained from the DCE and the BWM are compared by determining whether the difference in share of preference between two methods is statistically different. The preference ordering of the attributes between the two methods is also analyzed (i.e., which attribute is the most preferred and which is the least preferred within each method).
Data. The details of the demographic and household characteristics of the 1179 respondents from Florida, Georgia, Oklahoma, North Carolina, and Texas are shown in Table 3. The majority of the respondents are homeowners, and only households with lawns are included in this study. The demographics from the American Housing Survey for homeowners of the southern region were used to compare whether the demographics of this study are similar. Most of the demographics of this survey are representative of homeowners of the southern region of the United States. The median age of homeowners in the southern region is 55 years for 2013 (American Housing Survey, 2013). The median age of respondents across states in this study ranges from 50 to 56 years, with a standard deviation of $\approx 15$ years. Likewise, the median household income for owneroccupied households is $\$ 52,400$ for the southern region (American Housing Survey, 2013). The mean annual household income in this study ranges from $\$ 56,991$ in Oklahoma to $\$ 79,604$ in Texas, which is comparatively higher than the regional data. The majority of the respondents are female in all states except for respondents from Oklahoma and Texas. Mean lawn sizes of the respondents range from 0.37 to 0.66 acres across states, indicating that respondents have a larger lawn size in general than may be common in the southern region. For example, the average lawn size in the United States varies from state to state, ranging from 0.06 acre in Washington, DC, to 0.51 acre in Georgia (Chapman, 2015).

\section{Results and Discussion}

\section{Parameter estimates from the mixed logit}

Discrete choice experiment. The estimates of the variables for the DCE are given in Table 4. Coefficient estimates have the expected signs for all significant attributes. Most of the variables are significant except for the average price variable in all states. In addition, the winterkill attribute is significant only in Oklahoma. The parameters are estimated for all states pooled together and for individual states. The joint likelihood ratio test indicates that each individual state is statistically different from the pooled data. These coefficient estimates are used to calculate the share of preference for each attribute for the homeowners.

The shares of preferences for the attributes using the DCE are provided in Table 5. Pooling all states together, the most preferred attribute for turfgrass is low average maintenance cost $(53.6 \%)$, followed by shade-tolerant turf $(22.8 \%)$, and water-conserving turf $(18.8 \%)$. The least preferred attributes are low purchase price $(0.1 \%)$, winterkill-tolerant turf $(0.7 \%)$, and saline-tolerant turf $(4.0 \%)$. The relative preferences of turfgrass attributes for lawns using the DCE among individual states are slightly different. However, in each state, the three most preferred turfgrass attributes for homeowners are low average maintenance cost, shade tolerance, and water-conserving turf, whereas the least valued turfgrass attributes are low purchase price, winterkill tolerance, and saline tolerance. In Florida and Texas, low average maintenance cost is the most preferred attribute, followed by water-conserving and shade-tolerant turf. In Georgia, Oklahoma, and North Carolina, low average maintenance cost is the most preferred attribute, followed by shade-tolerant and waterconserving turf.

In all five states, low average purchase price is the least preferred attribute. Salinetolerant turf is more preferred than winterkilltolerant turf in Florida and Georgia, whereas winterkill-tolerant turf is more preferred than saline-tolerant turf in Oklahoma, North Carolina, and Texas. The share of preference for low-maintenance turf ranges from $42.4 \%$ (Georgia) to $59.1 \%$ (North Carolina). Shade-tolerant turf ranges from $16.5 \%$ (Florida) to $25.7 \%$ (Georgia), water-conserving turf ranges from $15.5 \%$ (Oklahoma and North Carolina) to $22.1 \%$ (Texas), salinetolerant turf ranges from $1.2 \%$ (North Carolina) to $14.8 \%$ (Georgia), and the winterkill attribute ranges from $1.1 \%$ (Georgia) to $5.4 \%$ (Oklahoma). The share of preference for the average purchase price attribute is insignificant and less than unity for all states. Price is a small factor for overall replacement of lawn or sod installation, which could also be a reason of the insignificance of the average price variable in the model.

Best-worst method. In the analysis of the BWM, one variable (winterkill-tolerant turf) is dropped to avoid perfect collinearity in the variables. The parameter estimates of the BWM are provided in Table 6. Similar to the DCE, parameters of the BWM are estimated for all states pooled together and for individual states. The joint likelihood ratio test for the BWM also indicates that each individual state is statistically different from the pooled data. The parameter estimates of the BWM are used to estimate the share of preference of each attribute through forecasted probabilities as in Eq. (7). Pooling all states together, the most preferred attribute using the BWM is low average maintenance cost $(44.9 \%)$, followed by drought-tolerant turf $(25.8 \%)$, and low average purchase price $(13.1 \%)$, whereas the least preferred attributes are saline-tolerant turf $(6.4 \%)$ and shade-tolerant turf $(9.8 \%)$ (Table 7). The drought tolerance attribute is the most preferred attribute in Texas, whereas low maintenance cost is the most preferred attribute in the other four states. The share of preference for low-maintenance turf ranges from $32.5 \%$ (Texas) to $50.6 \%$ (North Carolina), drought-tolerant turf ranges from $18.6 \%$ (Georgia) to $43.4 \%$ (Texas), low average purchase price of turf ranges from $9.7 \%$ (Texas) to $15.7 \%$ (North Carolina), shade-tolerant turf ranges from $7.3 \%$ (Florida) to $13.8 \%$ (Georgia), and saline-tolerant turf 
Table 3. Summary of the demographics of the respondents.

\begin{tabular}{|c|c|c|c|c|c|c|c|c|}
\hline \multirow[b]{2}{*}{ States } & \multicolumn{2}{|c|}{ Age (years) } & \multicolumn{2}{|c|}{ Household income (\$) } & \multirow[b]{2}{*}{ Female (\%) } & \multirow[b]{2}{*}{ Homeowners $(\%)$} & \multicolumn{2}{|c|}{ Lawn size (acres) } \\
\hline & Median & SD & Mean & SD & & & Mean & SD. \\
\hline Florida & 56 & 15 & 65,693 & 48,612 & 38 & 97 & 0.37 & 0.35 \\
\hline Georgia & 52 & 15 & 70,258 & 54,534 & 45 & 98 & 0.62 & 0.46 \\
\hline North Carolina & 54 & 14 & 67,624 & 49,770 & 46 & 99 & 0.66 & 0.47 \\
\hline Texas & 50 & 14 & 79,604 & 45,073 & 38 & 99 & 0.39 & 0.36 \\
\hline
\end{tabular}

Table 4. Parameter estimates for the discrete choice experiment (mixed logit).

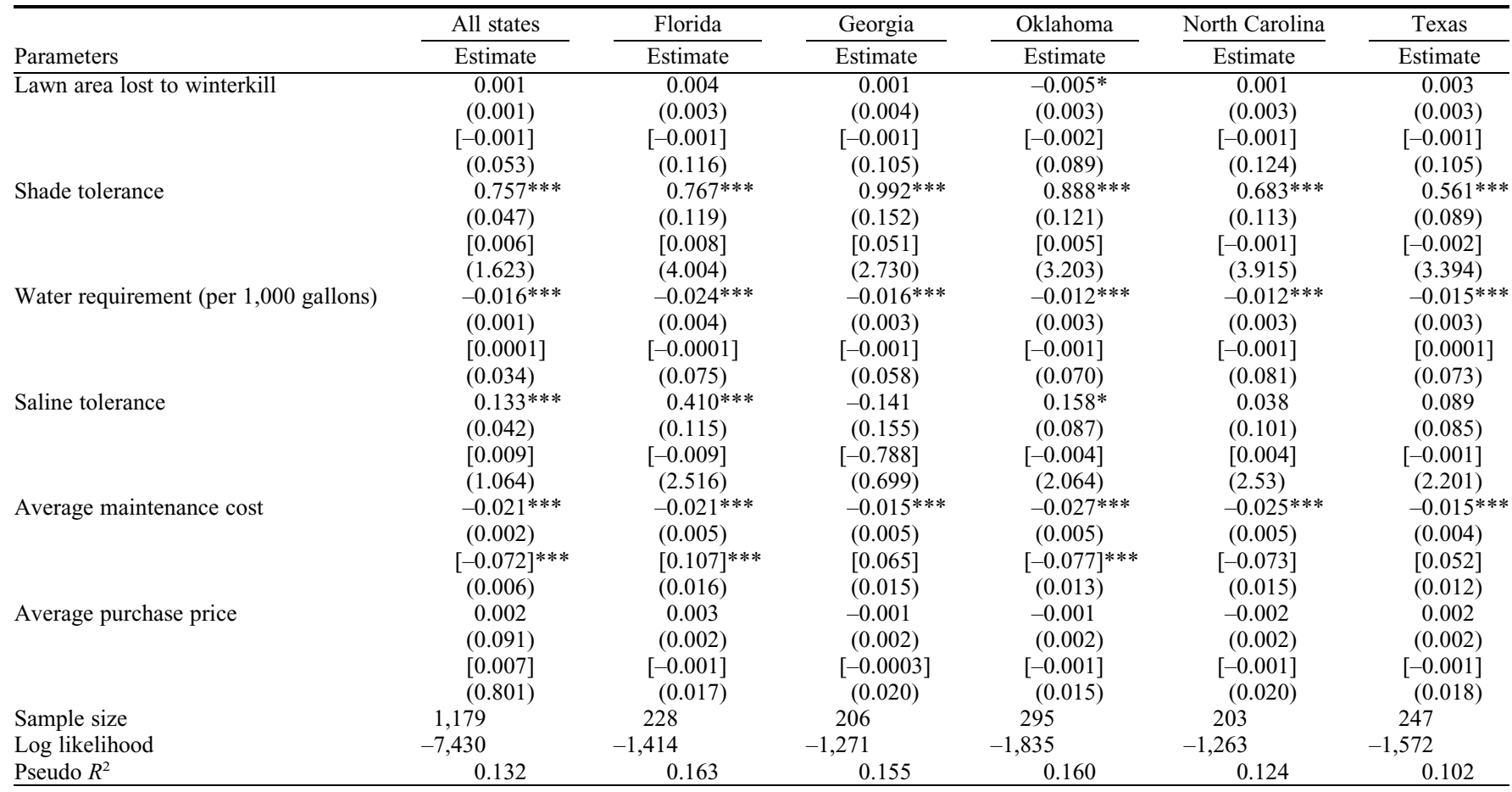

***and *represent significance at $1 \%$ and $10 \%$, respectively. Numbers in parentheses () are SE and numbers in brackets [] are SD.

Table 5. Shares of preferences of attributes using part-worth of the discrete choice experiment.

\begin{tabular}{|c|c|c|c|c|c|c|}
\hline \multirow[b]{2}{*}{ Attributes } & \multirow[b]{2}{*}{ All states } & \multicolumn{5}{|c|}{ Share of preference } \\
\hline & & Florida & Georgia & Oklahoma & North Carolina & Texas \\
\hline Shade tolerance & $0.228[0.100]$ & $0.165[0.069]$ & $0.257[0.095]$ & $0.239[0.101]$ & $0.226[0.114]$ & $0.212[0.087]$ \\
\hline Saline tolerance & $0.040[0.018]$ & $0.088[0.037]$ & $0.148[0.105]$ & $0.043[0.018]$ & $0.012[0.006]$ & $0.034[0.014]$ \\
\hline Low average maintenance cost & $0.536[0.204]$ & $0.505[0.204]$ & $0.424[0.198]$ & $0.510[0.207]$ & $0.591[0.207]$ & $0.488[0.209]$ \\
\hline Low average purchase price & $0.001[0.001]$ & $0.001[0.001]$ & $0.001[0.001]$ & $0.001[0.001]$ & $0.001[0.001]$ & $0.001[0.001]$ \\
\hline
\end{tabular}

Numbers in brackets [] are SD.

ranges from $1.8 \%$ (Oklahoma) to $11.9 \%$ (Florida).

Different factors such as latitude, soil characteristics, water availability, and weather conditions naturally affect demand for turfgrass varieties by state which drives heterogeneity in preferences among states. All five states experience some sort of intermittent drought; Oklahoma and Texas were in a state of severe drought at the time of this study in 2013 (Svoboda, 2014; Fernando et al., 2015). Parts of North Carolina, Texas, and Georgia are subject to salinity. The importance of cold hardiness in North Carolina and Oklahoma are based on latitude, and the USDA cold hardiness zone as winterkill is an important factor in these states in terms of bermudagrass and zoysiagrasses (D. Martin, personal communication).

\section{Comparison of shares of preferences of attributes between the DCE and the BWM}

A pairwise comparison of differences in the shares of preferences of turfgrass attributes between the DCE and the BWM is presented in Table 8 . The results show that the preference levels by the DCE and the BWM are statistically different. However, out of the top three most preferred attributes using the DCE, two attributes (low maintenance cost and drought-tolerant turf) are also two of the most preferred attributes using the
BWM (Table 7). In Florida, Georgia, Oklahoma, and North Carolina, the most preferred attribute for homeowners using both methods is low-maintenance turf (Table 7). The most notable difference between the two methods is observed with the shade-tolerant turf and average purchase price attributes (Table 8). The difference is relatively high for these two attributes in each state. The shade-tolerant turf attribute is one of the highly valued attributes using the DCE, but it is one of the least preferred attributes using the BWM. In addition, the average purchase price is the least preferred attribute in the DCE, whereas it is mostly ranked the third valued attribute in the BWM. The possible reason for this might be due to insignificant parameter 
Table 6. Parameter estimates from the best-worst method (mixed logit).

\begin{tabular}{|c|c|c|c|c|c|c|}
\hline & All states & Florida & Georgia & Oklahoma & North Carolina & Texas \\
\hline Parameters & Estimate & Estimate & Estimate & Estimate & Estimate & Estimate \\
\hline \multirow[t]{4}{*}{ Shade tolerance } & -0.055 & $0.268 * * *$ & $-0.188^{*}$ & $-0.255 * * *$ & $-0.373 * * *$ & 1.595 \\
\hline & $(0.037)$ & $(0.219)$ & $(0.101)$ & $(0.095)$ & $(0.104)$ & $(0.193)$ \\
\hline & {$[0.796] * * *$} & {$[0.018]$} & {$[-1.281]^{* * *}$} & {$[1.409] * * *$} & {$[0.921] * * *$} & {$[-1.418] * * *$} \\
\hline & $(0.109)$ & $(1.925)$ & $(0.256)$ & $(0.221)$ & $(0.275)$ & $(0.245)$ \\
\hline \multirow[t]{4}{*}{ Drought tolerance } & $1.0254 * * *$ & $1.225 * * *$ & $0.468 * * *$ & $1.272 * * *$ & $0.479 * * *$ & $1.996 * * *$ \\
\hline & $(0.057)$ & $(0.116)$ & $(0.092)$ & $(0.146)$ & $(0.102)$ & $(0.229)$ \\
\hline & {$[0.941]^{* * *}$} & {$[0.765]^{* * *}$} & {$[0.610] * * *$} & {$[-1.191]^{* * *}$} & {$[0.794] * * *$} & {$[-1.526] * * *$} \\
\hline & $(0.104)$ & $(0.218)$ & $(0.299)$ & $(0.229)$ & $(0.276)$ & $(0.259)$ \\
\hline \multirow[t]{4}{*}{ Saline tolerance } & $-1.369 * * *$ & $0.148 *$ & $-1.826 * * *$ & $-2.430 * * *$ & $-1.923 * * *$ & $-1.334 * * *$ \\
\hline & $(0.071)$ & $(0.083)$ & $(0.218)$ & $(0.225)$ & $(0.235)$ & $(0.165)$ \\
\hline & {$[1.786]^{* * *}$} & {$[1.346]^{* * *}$} & {$[-2.097]^{* * *}$} & {$[1.504]^{* * *}$} & {$[2.080] * * *$} & {$[1.979] * * *$} \\
\hline & $(0.111)$ & $(0.184)$ & $(0.303)$ & $(0.241)$ & $(0.313)$ & $(0.277)$ \\
\hline \multirow[t]{4}{*}{ Low average maintenance cost } & $1.593 * * *$ & $2.131 * * *$ & $1.479 * * *$ & $1.663 * * *$ & $1.758 * * *$ & $1.595 * * *$ \\
\hline & $(0.080)$ & $(0.185)$ & $(0.182)$ & $(0.178)$ & $(0.216)$ & $(0.192)$ \\
\hline & {$[-1.340]^{* * *}$} & {$[-1.246]^{* * *}$} & {$[-1.652]^{* * *}$} & {$[1.697]^{* * *}$} & {$[-1.595]^{* * *}$} & {$[-1.417] * * *$} \\
\hline & $(0.109)$ & $(0.216)$ & $(0.280)$ & $(0.243)$ & $(0.287)$ & $(0.254)$ \\
\hline \multirow[t]{4}{*}{ Low average purchase price } & $0.413 * * *$ & $0.842 * * *$ & $0.292 * * *$ & $0.174 * * *$ & $0.328 * * *$ & $0.475 * * *$ \\
\hline & $(0.037)$ & $(0.088)$ & $(0.083)$ & $(0.084)$ & $(0.093)$ & $(0.091)$ \\
\hline & {$[0.485]^{* * *}$} & {$[-0.585]^{* * *}$} & {$[-0.386]$} & {$[-1.002]^{* * *}$} & {$[-0.739]$} & {$[-0.571]$} \\
\hline & $(0.148)$ & $(0.249)$ & $(0.399)$ & $(0.233)$ & $(0.288)$ & $(0.351)$ \\
\hline Sample size & 1,179 & 228 & 206 & 295 & 203 & 247 \\
\hline Log likelihood & $-14,076$ & $-2,821$ & $-2,491$ & $-3,191$ & $-2,342$ & $-2,889$ \\
\hline Pseudo $R^{2}$ & 0.47 & 0.43 & 0.45 & 0.59 & 0.51 & 0.51 \\
\hline
\end{tabular}

$* * *, * *$, and *represent significance at $1 \%, 5 \%$, and $10 \%$, respectively. Numbers in parentheses () are SE and numbers in brackets [] are SD.

Table 7. Shares of preferences of attributes using the best-worst method.

\begin{tabular}{|c|c|c|c|c|c|c|}
\hline Attributes & All states & Florida & Georgia & Oklahoma & North Carolina & Texas \\
\hline Shade tolerance & $0.098[0.096]$ & $0.073[0.043]$ & $0.138[0.158]$ & $0.105[0.144]$ & $0.093[0.103]$ & $0.093[0.112]$ \\
\hline Drought tolerance & $0.258[0.197]$ & $0.219[0.163]$ & $0.186[0.144]$ & $0.313[0.252]$ & $0.187[0.156]$ & $0.434[0.287]$ \\
\hline Saline tolerance & $0.064[0.116]$ & $0.119[0.147]$ & $0.062[0.129]$ & $0.018[0.038]$ & $0.056[0.117]$ & $0.052[0.109]$ \\
\hline Low average maintenance cost & $0.449[0.262]$ & $0.451[0.258]$ & $0.464[0.283]$ & $0.441[0.302]$ & $0.506[0.287]$ & $0.325[0.263]$ \\
\hline Low average purchase price & $0.131[0.098]$ & $0.138[0.101]$ & $0.149[0.116]$ & $0.123[0.140]$ & $0.157[0.140]$ & $0.097[0.096]$ \\
\hline
\end{tabular}

Numbers in brackets [] are SD.

Table 8. Differences in share of preferences for attributes between the discrete choice experiment (DCE) and the best-worst method (BWM).

\begin{tabular}{|c|c|c|c|c|c|c|}
\hline & All states & Florida & Georgia & Oklahoma & North Carolina & Texas \\
\hline Attributes & DCE-BWM & DCE-BWM & DCE-BWM & DCE-BWM & DCE-BWM & $\overline{\mathrm{DCE}-\mathrm{BWM}}$ \\
\hline Shade tolerance & $0.130 * *$ & $0.092 * *$ & $0.119 * *$ & $0.134 * *$ & $0.133 * *$ & $0.119 * *$ \\
\hline Drought tolerance & $-0.070 * *$ & $-0.011 * *$ & $-0.025 * *$ & $-0.158 * *$ & $-0.032 * *$ & $-0.213 * *$ \\
\hline Saline tolerance & $-0.024 * *$ & $-0.031 * *$ & $0.086 * * *$ & $0.025 * *$ & $-0.044 * *$ & $-0.018 * *$ \\
\hline Low average maintenance cost & $0.087 * *$ & $0.054 * *$ & $-0.040 * *$ & $0.069 * *$ & $0.085 * *$ & $0.163^{* *}$ \\
\hline Low average purchase price & $-0.130 * *$ & $-0.137 * *$ & $-0.148 * *$ & $-0.122 * *$ & $-0.156^{* *}$ & $-0.096 * *$ \\
\hline
\end{tabular}

**Represents significance at 5\% level. A pairwise $t$ test shows a significant difference between two methods.

estimates for the average purchase price attribute in the DCE. In Texas, the difference in the share of preference for the drought tolerance attribute is high as the respondents value the drought tolerance attribute more in the BWM, whereas the low maintenance cost attribute is valued more in the DCE (Table 7). Though the shares of preferences are statistically different between the two methods, the ordering in the shares of preferences is similar except for the average purchase price and shade-tolerant turf attributes (Table 8). Previous studies have reported similarities (Potoglou et al., 2011) as well as differences in estimates of attributes from these two methods (Whitty et al., 2014). Similar to this study, Whitty et al. (2014) also reports differences between the two methods, but a similar ordering of the attributes.

Homegeneity in shares of preferences of the attributes among states and the larger $R^{2}$ in this study indicate that the BWM could be a better method to elicit relative preferences for attributes of a product. However, the variances of attributes for most of the variables in the DCE are lower compared with the BWM, which might support the use of the DCE. Thus, there is no clear indication of one method being better than the other. Some studies argue that the BWM is preferable as there is only one option to choose either the "most" or "least" preferred, and there is a lower probability of bias in the rating scale (Cohen and Markowitz, 2002). However, studies also suggest that the DCE is a more feasible and reliable method to elicit the preferences, since the BWM becomes complicated due to the difficulty of making the shift among attributes while choosing the best and worst options (Xie et al, 2012).

\section{Summary and Conclusions}

This study compares the shares of preferences of stress-tolerant, low-maintenance, and low-cost turfgrass attributes using the DCE and the BWM in five states (Florida, Georgia, North Carolina, Oklahoma, and Texas) in the southeastern and midsouthern United States. An online survey among homeowners was conducted, and the MLM was used for analysis of both methods to determine the relative preference of turfgrass attributes for the homeowners. The results of a survey of 1179 household consumers indicate that the most preferred attribute using either of the methods is low maintenance cost in all the states. Although the shares of preferences by the DCE and the BWM are statistically different, both methods yield a similar preference ordering for attributes such as low-maintenance, drought-tolerant, and saline-tolerant turfgrasses. However, the preference ordering for shade-tolerant turf and low-priced turf is different in the two methods. In the context of this study, the DCE could be a more appropriate gauge of the market for use by turf wholesalers due to 
the inclusion of an actual price variable and the respondents' ability to indirectly choose an option and make a trade-off among a set of scenarios. In addition, the BWM may not perform well in a priority setting context for applied marketing studies (Whitty et al., 2014). However, the ambiguity about methods warrants further study about the selection of the best method. The large standard deviations in the shares of preferences of attributes indicate that there is heterogeneity in the relative importance of turfgrass attributes.

Overall, this study provides an early insight into the use of preference share scales to rank the stress-tolerant, low-maintenance, and low-cost turfgrass attributes. This study gives a notable outcome in reconfirming the findings from Yue et al. (2012) that people value low-maintenance turf the most using both methods. In addition, drought-tolerant and shade-tolerant turf are also high on the homeowners' priority list. Thus, this study provides framework for the warm-season turfgrass researchers and producers to invest and expand outreach on desirable turfgrass attributes for the homeowners.

\section{Literature Cited}

American Housing Survey. 2013. AHS 2013 National Summary Tables. 13 Aug. 2015. <http:// www.census.gov/programs-surveys/ahs/data/2013/ ahs-2013-summary-tables/national-summaryreport-and-tables-ahs-2013.html>.

Auger, P., T.M. Devinney, and J. Louviere. 2007. Using best-worst scaling methodology to investigate consumer ethical beliefs across countries. J. Bus. Ethics 70(3):299-326.

Bleichrodt, H. 2002. New explanation for the difference between time trade-off utilities and standard gamble utilities. Health Econ. 11:447-456.

Bormann, F.H., D. Balmori, and G.T. Geballe. 2001. Redesigning the American lawn: A search for environmental harmony. Yale University Press, New Haven and London.

Chapman, E. 2015. Lawn size. 7 May 2015. <http:// grounds-mag.com/mag/grounds_maintenance_ lawn_size/>.

Cheraghi, S., A.R. Hole, N. Mead, R. McDonald, D. Whalley, P. Bower, and M. Roland. 2008. What patients want from primary care consultations: A discrete choice experiment to identify patients' priorities. Ann. Fam. Med. 6(2): $107-115$.

Cohen, S.H. and P. Markowitz. 2002. Renewing market segmentation: Some new tools to correct old problems. Paper presented at the ESOMAR 2002 Congress Proceeding. p. 595-612).
Ferguson, B.K. 1987. Water conservation methods in urban landscape irrigation: An exploratory overview. Water Resour. Bull. 23:147-152.

Fernando, N., R. Fu, R.S. Solis, R.E. Mace, Y. Sun, B. Yang, and B. Pu. 2015. Early warning of summer drought over Texas and the south central United States: Spring conditions as a harbinger of summer drought. Technical Note 15-02, Texas Water Development Board.

Finn, A. and J.J. Louviere. 1992. Determining the appropriate response to evidence of public concern: The case of food safety. J. Pub. Pol. Market. 11:12-25.

Flynn, T.N., J.J. Louviere, T.J. Peters, and J. Coast. 2007. Best-worst scaling: What it can do for health care research and how to do it. J. Health Econ. 26(1):171-189.

Frank, W.K. 2013. Freeze injury on turf. 29 Nov 2014. <http://msuturf.blogspot.com/2013/05/ freeze-injury-on-turf.html $>$.

Goodman, S.P., L. Lockshin, and E. Cohen. 2005. Best-worst scaling: A simple method to determine drinks and wine style preferences. International Wine Marketing Symposium. Sonoma, CA.

Harivandi, A. and V. A. Gibeault. 1996. Managing lawns in shade. University of California Division of Agricultural and Natural Resource Publication 7214, Oakland, CA.

Haydu, J.J., A.W. Hodges, and C.R. Hall. 2006. Economic impacts of the turfgrass and lawncare industry in the United States. Univ. Florida, Coop. Ext. Serv., Gainesville, FL. EDIS Bull. FE632. 10 Apr. 2014. <http://edis.ifas.ufl. edu/FE632>.

Hensher, D.A. and W.H. Greene. 2003. The mixed logit model: The state of practice. Transport 30(2):133-176.

Kenny, J.F., L. B. Nancy, S.H. Susan, S. L. Kristin, K. L. John, and A.M. Molly. 2009. Estimated use of water in the United States in 2005. U.S. Geological Survey. No. 1344.

Kjelgren, R., L. Ruppi, and D. Kilgren. 2000 Water conservation in urban landscapes. HortScience 35:1037-1040.

Lancsar, E. and J. Louviere. 2008. Conducting discrete choice experiments to inform healthcare decision making. Pharmacoeconomics 26(8):661-677.

Louviere, J.J. and G. Woodworth. 1983. Design and analysis of simulated consumer choice or allocation experiments: An approach based on aggregate data. J. Mark. Res. 20(4):350-367.

Louviere, J.J., D.A. Hensher, and J.D. Swait. 2000 Stated choice methods: Analysis and applications. Cambridge University Press.

Lusk, J.L. and B.C. Briggeman. 2009. Food values. Amer. J. Agr. Econ. 9(1):184-196.

Mayer, P.W., W.B. Deoreo, E.M. Opitz, J.C. Kiefer, W.Y. Davis, B. Dziegielewski, and J.O. Nelson. 1999. Residential end uses of water. AWWA Research Foundation and American Water Works Association, Denver, CO.
McFadden, D. and K. Train. 2000. Mixed MNL models for discrete response. J. Appl. Econ. 15(5):447-470.

Milesi, C., C.D. Elvidge, J.B. Dietz, B.T. Tuttle, R.R. Neimani, and S.W. Running. 2005. A strategy for mapping and modeling the ecological effects of US lawns. J. Turfgrass Mgt. 1:83-97.

Morris, K. National turfgrass research initiative. 2003. National Turfgrass Federation, Inc., and National Turfgrass Evaluation Program, Beltsville.

Murdoch, C.L. 1987. Water: The limiting factor for golf course development in Hawaii. 1987. New York.

Orme, B. 2010. Interpreting the results of conjoint analysis, getting started with conjoint analyis: Strategies for product design and pricing research. Res. Publ. LLC Madison WI, 77-89.

Potoglou, D., P. Burge, T. Flynn, A. Netten, J. Malley, J. Forder, and J.E. Brazier. 2011. Bestworst scaling vs. discrete choice experiments: An empirical comparison using social care data. Soc. Sci. Med. 72(10):1717-1727.

Ryan, M. and K. Gerard. 2003. Using discrete choice experiments to value health care programs: Current practice and future research reflections. Appl. Health Econ. Health Policy 2(1):55-64

Solley, W.B., R.R. Pierce, and H.A. Perlman. 1998. Estimated use of water in the United States in 1995 (USGS Circular 1200). USGS. Reston, VA. p. 27. Stat 80:647-657.

Svoboda, M. 2014. Oklahoma drought monitor map. 16 July 2015. <https://www.mesonet.org/ index.php/agriculture/map/agriculture_essentials/ drought/oklahoma_drought_monitor_map > .

Train, K. 2003. Discrete choice methods with simulation. Cambridge University Press, Cambridge, UK.

USDA-NASS. 2015. USDA/NASS QuickStats Adhoc Query Tool. 15 May 2016. <http://quickstats. nass.usda.gov/results/AD53AB7B-6317-3E8C9E0D-6DBF61E39DB5>

Vickers, A. 2001. Handbook of water use and conservation. Water Plow Press, Amherst, MA.

Whitty, J.A., J. Ratcliffe, G. Chen, and P.A. Scuffham. 2014. Australian public preferences for the funding of new health technologies: a comparison of discrete choice and profile case best-worst scaling methods. Med. Decis. Making 34:638-654.

Xie, F., E. Pullenayegum, K. Gaebel, M. Oppe, and P.F.M. Krabbe. 2012. PIH39 Eliciting preferences to the EQ-5D-5L health states: Discrete choice experiment or multiprofile case of bestworst scaling. Value Health 15(1):A198-A199.

Yue, C., H. Kari, and E. Watkins. 2012. Are consumers willing to pay more for low-input turfgrasses on residential lawns? Evidence from choice experiments. J. Agr. Appl. Econ. 44(4):549-560. 